\title{
Stabilization of Constant-on Time Controlled Buck Converter
}

\author{
Wei, HU \\ Lab Center \\ Guangzhou University \\ Guangzhou, China \\ pehuwei@gzhu.edu.cn
}

\author{
Fangying, ZHANG \\ Lab Center \\ Guangzhou University \\ Guangzhou, China \\ zfy@gzhu.edu.cn
}

\begin{abstract}
Constant-on time voltage feedback controlled Buck converter is one kind of typical nonlinear system. It produces unstable behavior in the running of the system. With the change of output electric capacity ESR, bifurcation and chaos behaviors are shown in the system. The mechanism that produced the phenomenon is analyzed by using the Floquet theory and stabilization method to control the instabilities of the converter is proposed as well. Analysis shows that the method widens the stability boundary of Buck converter and is in favor of the system steady running. The simulation result proves that the accuracy of theoretical analysis.
\end{abstract}

Keywords-Constant-on time; Buck converter; Stabilization; Floquet theory; DC-DC converter

\section{INTRODUCTION}

As one kind of typical topology in switching converter, Buck converter is widely applied in industry and civilian systems[1]. This converter usually adopts PWM controlling methods[2], regulates output voltage and inductor current, and gets the desired output results. The present study shows that Buck converter controlled PWM is one nonlinear system. It will produce nonlinear behaviors such as period doubling bifurcation[3], Hopf bifurcation[4], multi volume cycle[5], chaos[6] and so on. Comparatively, unstable behavior of Buck converter that is regulated by impulse frequency is studied rarely. The document[7] researched that the bifurcation behavior of Constant-on time controlled Buck converter. The results showed that with the change of output electric capacity ESR, the system produced obvious bifurcation and chaos phenomenon. The document[8] analyzed the stability of the system that finite-off time controlled Buck converter with the change of output capacitance. But these documents analyzed neither if the unstable behavior was produced when constant-on time controlled Buck converter changed, nor presented the method of stabilization the closed-loop system and extension the stability boundary of circuit parameters.

So this paper established the discrete model of Constant-on time controlled Buck converter, analyzed the unstable behavior when Constant-on time controlled Buck converter changed, discussed the bifurcation path, and showed phase diagram of period doubling bifurcation, multi volume period bifurcation and chaos of the system. Based on Floquet theory [9] and the monodromy matrix theories[10, 11], this paper proposed the method that controlled the unstable behavior and expand the stability boundary of system, finally make chaos behavior of system stable one periodic stable.

The second section of this paper shows the schematic of the entire system and established the discrete model. Third section analyzed the bifurcation behavior of closed loop system. The fourth section researched deeply the method of stabilization the converter. The last section is conclusion.

\section{DISCRETE-TIME MODEL OF THE COT CONTROLLED BUCK CONVERTER}

The schematic and mainly operation waveforms are as Fig .1 (a) and (b) shown, separately. The constant-on time (COT) controller is composed of comparator, ON-Timer, and R-S flip-flop. As the output voltage $u_{\mathrm{o}}$ of the converter is lower than the reference $U_{r}$, the output of the R-s flip-flop becomes high and the switching tube is turned on. Therefore, the $u_{\mathrm{o}}$ goes high gradually, and the ON time interval of the switching tube is determined by the COT controller. After the COT time interval passes by, a narrow pulse is export by the COT controller, and the R$\mathrm{S}$ flip-flop is reset. The switching tube is turned off after that, the voltage value of $u_{\mathrm{o}}$ is getting small. As the output voltage reaches $U_{r}$, the switching tube is turned on again, and the next operational period is start.

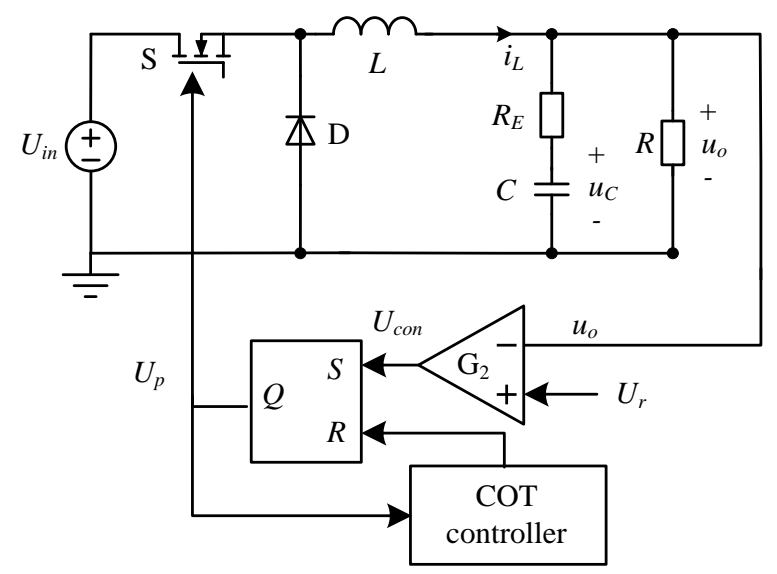

(a) Schematic of the COT controlled Buck converter 


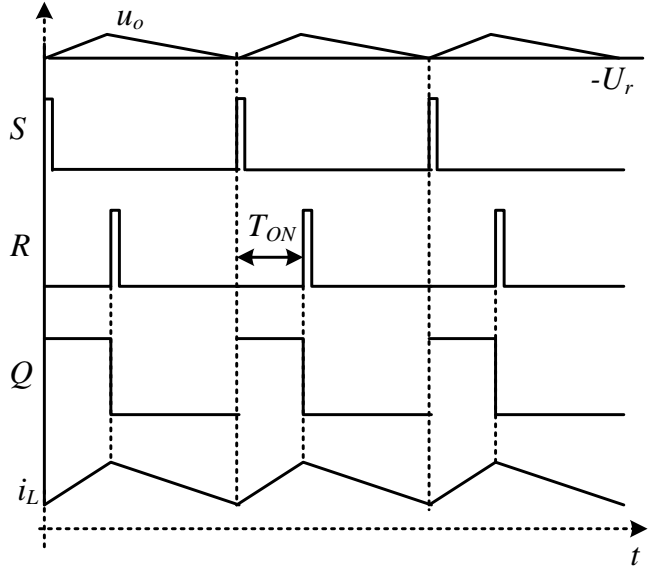

(b) Operation waveforms

Figure 1. Schematic and waveforms of the COT controlled Buck converter

The State matrices and the Output matrices are shown in Tab. I.

TABLE.I. BUCK CONVERTER MATHEMATICAL MODEL

\begin{tabular}{cc}
\hline State matrix & Output matrix \\
\hline $\boldsymbol{A}_{1}=\frac{1}{\left(R+R_{E}\right)}\left[\begin{array}{rr}-\frac{R R_{E}}{L} & -\frac{R}{L} \\
\frac{R}{C} & -\frac{1}{C}\end{array}\right]$ & $\boldsymbol{B}_{1}=\left[\begin{array}{l}\frac{1}{L} \\
0\end{array}\right]$ \\
$\boldsymbol{A}_{2}=\frac{1}{\left(R+R_{E}\right)}\left[\begin{array}{cc}-\frac{R R_{E}}{L} & -\frac{R}{L} \\
\frac{R}{C} & -\frac{1}{C}\end{array}\right]$ & $\boldsymbol{B}_{2}=\left[\begin{array}{l}0 \\
0\end{array}\right]$
\end{tabular}

By the control strategy we have

$$
U_{r}-U_{o}=0 \text {. }
$$

And because

$$
\begin{aligned}
& U_{O}=\Delta i_{L} R_{E}+U_{C}, \\
& \Delta i_{L}=i_{L}-\frac{u_{C}}{R},
\end{aligned}
$$

control strategy can be rewritten as

$$
U_{r}-\left(i_{L}-\frac{u_{C}}{R}\right) R_{E}-u_{C}=0 .
$$

Normal vector is as shown

Also, we have

$$
\boldsymbol{n}=\left[\begin{array}{c}
-R_{E} \\
-1+R_{E} / R
\end{array}\right] \text {. }
$$

$$
\Delta h=0 .
$$

By the document[12] as CCM Buck converter, iterative equation of switching point is:

$$
\begin{gathered}
e^{\boldsymbol{A}_{1} d T} \boldsymbol{x}(n T)+\boldsymbol{A}_{1}^{-1}\left(e^{\boldsymbol{A}_{1} d T}-\boldsymbol{I}\right) \boldsymbol{B}_{1} U_{i n}-\boldsymbol{x}(n T+d T)=0, \\
e^{\boldsymbol{A}_{2}(1-d) T} \boldsymbol{x}(n T+d T)+\boldsymbol{A}_{2}^{-1}\left[e^{\boldsymbol{A}_{2}(1-d) T}-\boldsymbol{I}\right] \boldsymbol{B}_{2} U_{i n} \\
-\boldsymbol{x}[(n+1) T]=0
\end{gathered}
$$

Discrete model of closed-loop system is:

$$
\begin{array}{r}
\boldsymbol{x}[(n+1) T]=e^{\boldsymbol{A}_{2}(1-d) T}\left[e^{\boldsymbol{A}_{1} d T} \boldsymbol{x}(n T)+\boldsymbol{A}_{1}^{-1}\left(e^{\boldsymbol{A}_{1} d T}-\boldsymbol{I}\right) \boldsymbol{B}_{1} U_{i n}\right] \\
+\boldsymbol{A}_{2}^{-1}\left[e^{\boldsymbol{A}_{2}(1-d) T}-\boldsymbol{I}\right] \boldsymbol{B}_{2} U_{i n}
\end{array}
$$

\section{THE BIFURCATION BEHAVIOR}

In order to facilitate the analysis, we select circuit parameters as shown in the Tab. II.

TABLE. II. COT CONTROLLED BUCK CONVERTER CIRCUIT PARAMETERS

\begin{tabular}{cccc}
\hline parameter & value & parameter & value \\
\hline$U_{\text {in }}$ & $15 \mathrm{~V}$ & $L$ & $200 \mu \mathrm{H}$ \\
\hline$R$ & $8 \Omega$ & $C$ & $100 \mu \mathrm{F}$ \\
\hline$R_{E}$ & $0.03 \Omega$ & $U_{r}$ & $5 \mathrm{~V}$ \\
\hline
\end{tabular}

As we all know, the output of the R-s flip-flop becomes high and the switching tube is turned on when the output voltage reaches $U_{r}$. And $u_{\mathrm{o}}$ goes high gradually, and the ON time interval of the switching tube is determined by the COT controller. After the COT time interval passes by, a narrow pulse is export by the COT controller, and the R$\mathrm{S}$ flip-flop is reset. The switching tube is turned off after that, the voltage value of $u_{\mathrm{o}}$ is getting small. As the output voltage reaches $U_{r}$, the switching tube is turned on again, and the next operational period is start.

At the time instant as the switching tube turns off, if the output voltage still lower than $U_{r}$, the switching tube will remains off state, and enters the next switching period. In such case, the multi-switching period oscillation occurs. Till the output voltage becomes higher than Ur at the switching off time instant, the COT controller recovered.

When $T_{o n}$ in COT controlled Buck converter changes, the system output signal will change. As COT time interval is decreased, output voltage and inductor current will from stable one periodic state, Multi volume period bifurcation to chaos. The circuit system is simulated using PSIM simulation software. Output voltage waveform obtained is shown as this section.

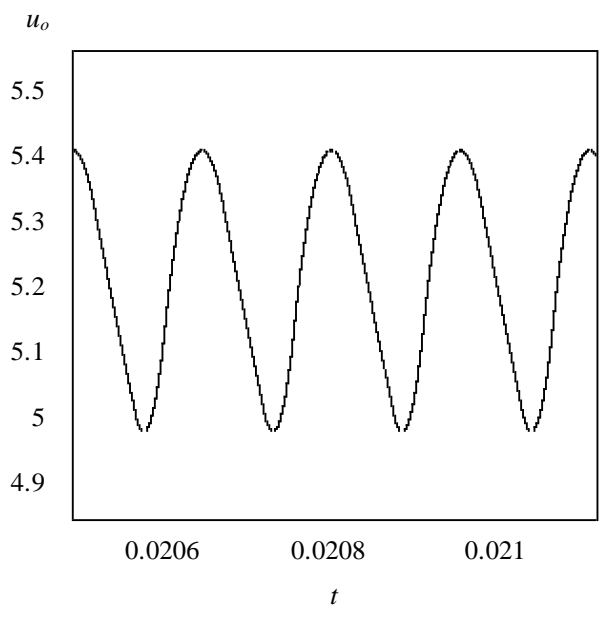

Figure 2. $T_{o n}=37.5 \mathrm{u}$, period- 1 state 
When $T_{\text {on }}=37.5 \mathrm{u}$, output voltage is stable one periodic state, and the simulation waveform is shown as Fig .2.

As $T_{o n}$ equals to $25 \mathrm{u}$, output voltage enters period doubling bifurcation, and the simulation waveform is shown as Fig .3.



Figure 3. $T_{o n}=25 \mathrm{u}$, period doubling bifurcation

When $T_{o n}$ is $17.5 \mathrm{u}$, output voltage is two volume of periodic bifurcation, and simulation waveform is shown as Fig .4.

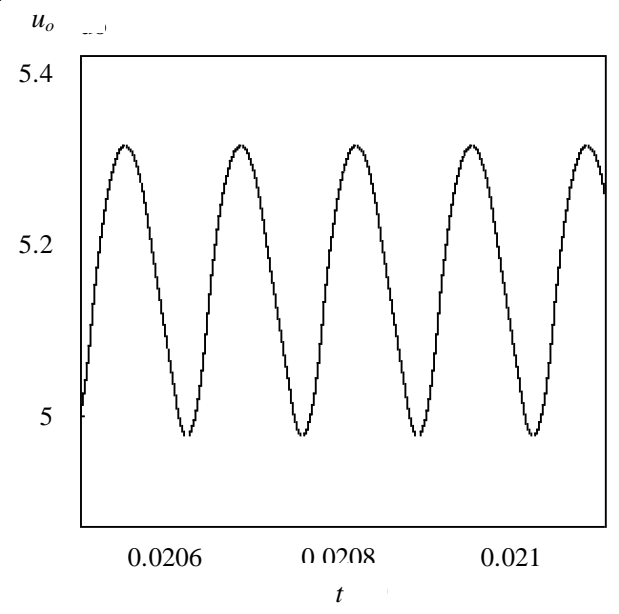

Figure 4. $T_{o n}=17.5 \mathrm{u}$, two volume of periodic bifurcation

When $T_{o n}$ is $10 \mathrm{u}$, output voltage enters unstable chaos state, and simulation waveform is shown as Fig .5.

\section{STABILIZATION OF BIFURCATION BEHAVIORS}

For chaos phenomena of COT controlled Buck converter is controlled, and the system is stabled to stable one periodic state, the section proposes that the inductor current is sampled, and one voltage feedback loop method is added. The schematic diagram is shown as Fig .6.

By the control strategy that:

$$
U_{r}-u_{O}-u_{s}=0 \text {, }
$$

so the control strategy is rewritten as

$$
U_{r}-\left(i_{L}-\frac{u_{C}}{R}\right) R_{E}-u_{C}-i_{L} R_{s}=0 .
$$

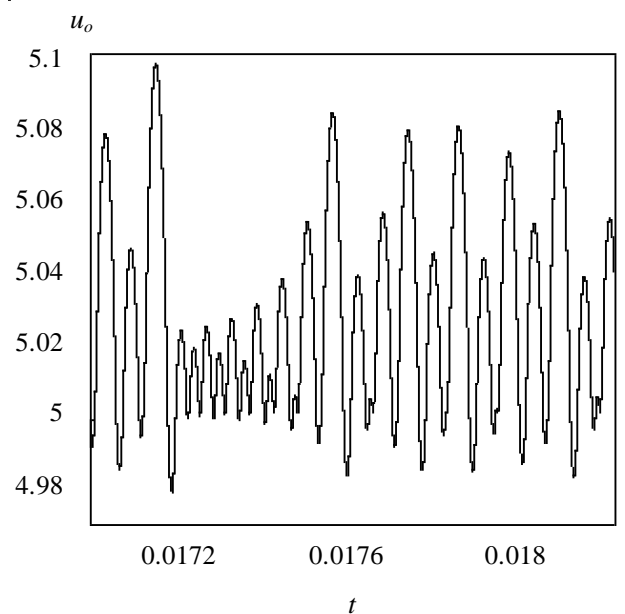

Figure $5 . \mathrm{COT}=10 \mathrm{u}$, chaos.

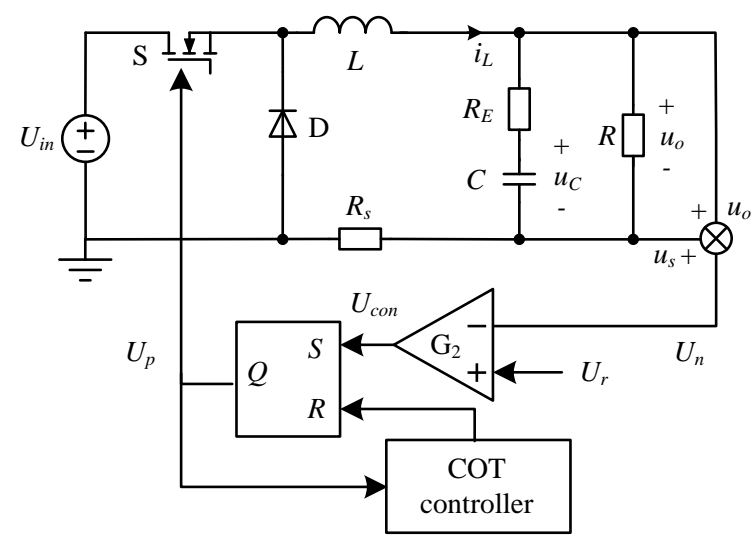

Figure 6. Schematic of the stabilized COT controlled Buck converter

TABLE. III. BUCK CONVERTER MATHEMATICAL MODEL

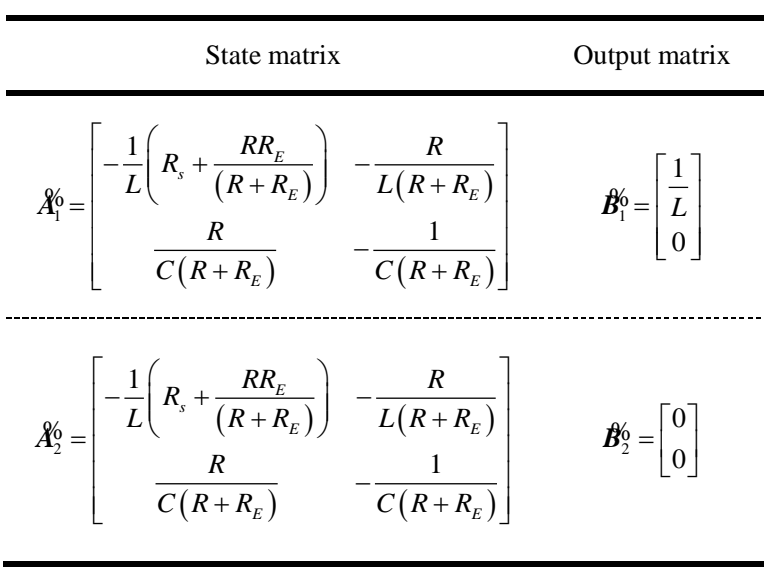

Mathematical model is shown as Tab. III.

Normal vector is as shown

Also, we have

$$
\boldsymbol{H}_{0}=\left[\begin{array}{c}
-R_{E}-R_{s} \\
-1+R_{E} / R
\end{array}\right] \text {. }
$$

$$
\Delta h=0 .
$$

The state vector of the entire system are as follows: 


$$
\begin{aligned}
& f_{1}^{\prime o}=\not_{1}^{\prime} x+\boldsymbol{B}_{1}^{\prime} U_{\text {in }} \\
& \boldsymbol{f}_{2}^{\prime o}=\boldsymbol{A}_{2}^{o} \boldsymbol{x}+\boldsymbol{B}_{2}^{o} U_{\text {in }}
\end{aligned}
$$

With respect to a CCM Buck converter, iterate equation of switching point can be written as [13] shows:

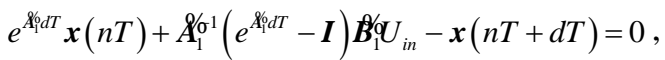

$$
\begin{aligned}
& e^{\mathbb{X}_{2} d^{2} T} \boldsymbol{x}(n T+d T)+\mathscr{A}_{2}^{101}\left[e^{\mathbb{X}_{2} d^{\prime} T}-\boldsymbol{I}\right] \boldsymbol{B}_{2}^{o} U_{i n}-\boldsymbol{x}[(n+1) T]=0 .
\end{aligned}
$$

where, $d$ is the duty cycle, and $d^{\prime}=1-d$.

Solving the above equations by MATLAB numerically with the Newton-Raphson method, the values of $\boldsymbol{x}$ and duty cycle $d$ can be obtained for the periodic orbit.

Based on Eqs. (12), (13), (14) and (15), the saltation matrix is shown as follows

$$
S^{\circ}=\boldsymbol{I}+\frac{\left[f_{2}^{\circ}-f_{1}^{f}\right] \boldsymbol{n}^{T}}{\boldsymbol{h}^{T} f_{1}^{\prime /}+\Delta h}
$$

It is clear that the following inequality is true

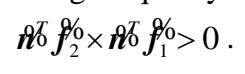

Therefore, there is only one Filippov solution in the switching surface of the system [26], and the Monodromy matrix over one switching period can be shown like

$$
M^{*}=\oiint_{2}^{o} \Phi_{o f f} \boldsymbol{S}_{1}^{/ \Phi_{o n}}=\Phi_{o f f} \boldsymbol{S}_{1}^{/ \Phi_{o n}}
$$

After the perturbation is applied, the switching surfaces in the Fig .7 is as follows. The converter was forced back to stable period-1 orbit.

When $R_{s}=0.2 \Omega$, the inductor current sampling signal adds to one voltage feedback loop, output waveform is shown as Fig .7. after stabilization. It can be seen from the graph that output voltage presents obvious one periodic steady state.



Figure 7. $T_{o n}=10 \mathrm{u}, R_{s}=0.2 \Omega$, one periodic steady state

\section{CONCLUSIONS}

The COT controlled Buck converter shows period doubling bifurcation and multi volume period bifurcation phenomena. The studies have shown that with gradually reduce of COT time interval, closed-loop system is from stable one periodic state, to period doubling bifurcation, to multi volume period bifurcation, in the end to unstable chaos state. So COT time interval becomes key point in engineering application. Sampling the inductor current and adding to one voltage feedback loop can stabilize unstable output voltage to stable one periodic state. Simulation results prove that analysis accuracy. Results of this paper can be used to guide the parameter design of COT controlled Buck converter. It has theoretical guidance significance for the industrial application.

\section{ACKNOWLEDGMENT}

Project supported by the Scientific Research Projects (the general project of science and engineering)of Guangzhou City-belong University (Grant No. 1201420871, 1201420679) from Guangzhou City Bureau of Education. Project Also supported by the Twelfth FiveYear Educational Science Plan Project of Guangzhou City (Grant No. 2013A060, 2013A038).

\section{REFERENCES}

[1] R. W. Erickson and D. Maksimovic, "Fundamentals of power electronics," Springer Science \& Business Media, 2001.

[2] R. E. Strawser, B. T. Nguyen and M. K. Kazimierczuk, "Analysis of a buck PWM DC-DC converter in discontinuous conduction mode" Proc. IEEE National Aerospace and Electronics Conference, 1994, pp. 35-42.

[3] C. K. Tse, "Flip bifurcation and chaos in three-state boost switching regulators," IEEE Trans. Circuits Syst. I Fundam. Theory Appl., vol. 41, no. 1, 1994, pp. 16-23.

[4] A. El Aroudi, L. Benadero, and E. Toribio et al., "Hopf Bifurcation and Chaos from Torus Breakdown in a PWM Voltage-Controlled DC-DC Boost Converter," IEEE Trans. Circuits Syst. I, Fundam. Theory Appl., vol. 46, no. 11, 1999, pp. 1374-1382.

[5] C. C. Fang, "Bifurcation boundary conditions for current programmed PWM DC-DC converters at light loading," Int. J. Electron., vol. 99, no. 10, Apr. 2012, pp. 1365-1393.

[6] P. Deivasundari, G. Uma, K. Murali, "Chaotic dynamics of voltage-mode controlled buck converter with periodic interference signals," Int. J. Bifurcat. Chaos, vol. 23, no. 6, Jun. 2013, pp.

[7] J. P. Wang, J. P. Xu and Y. J. Xu, "Analysis of multi-switching period oscillation phenomenon in constant on-time controlled buck converter," Acta Phys. Sin., vol. 60, no. 5, 2011, pp. 058401.

[8] X. Zhang, B. C. Bao, J. P. Wang, et al., :Stability analysis of equivalent series resistance of output capacitor in fixed off-time controlled Buck converter," Acta Phys. Sin., vol. 61, no. 16, 2012, pp. 160503.

[9] A. F. Filippov, "Differential Equations with Discontinuous Righthand Side," American Mathematical Society Translations, vol. 42, no. 2, 1964, pp. 199-231.

[10] D. Giaouris, S. Banerjee, and B. Zahawi et al., "Stability Analysis of the Continuous-Conduction-Mode Buck Converter Via Filippov's Method," IEEE Trans. Circuits Syst. I, Reg. Papers, vol. 55, no. 4, May. 2008, pp. 1084-1096.

[11] R. I. Leine, D. H. VAN Campen, and B. L. VAN DE VRANDE, "Bifurcations in Nonlinear Discontinuous Systems," Nonlinear Dynam., vol. 23, 2000, pp. 105-164.

[12] W.Hu, F. Y. Zhang, X. L. Long, X. B. Chen and W.T. Deng, "Stability Analysis and Control of Nonlinear Behavior in $\mathrm{V}^{2}$ Switching Buck Converter," Journal of Power Electronics, vol.14, no.6, 2014, pp.1208-1216.

[13] D. Giaouris, S. Banerjee, and B. Zahawi et al., "Stability Analysis of the Continuous-Conduction-Mode Buck Converter Via Filippov's Method," IEEE Trans. Circuits Syst. I, Reg. Papers, vol. 55, no. 4, pp. 1084-1096, May. 2008. 